\title{
The Role of Ultrasonography in Rheumatology ${ }^{*}$
}

\author{
Kok Ooi Kong, $\mathrm{MRCP}^{(1)}$, Damien Loeuille, $\mathrm{MD} \mathrm{PhD}^{(2)}$, Yohei Seto, $\mathrm{MD}^{(3)}$, \\ Richard J. Wakefield, MRCP ${ }^{(4)}$, Paul Emery, FRCP ${ }^{(5)}$
}

M sculoskeletal ultrasound (US) is rapidly evolving into an important method for confirming the primary diagnosis and monitoring therapeutic response in many rheumatic conditions. Diagnosis US has achieved great advances since the reported detection of Baker's cyst with B-mode scans in the early $1970 \mathrm{~s}^{(1)}$. Medical US was well developed in the 1980s when linear, sector, and Doppler US became available. However, the value of musculoskeletal US and its contribution in rheumatology were not widely recognized until 1990s when high-resolution US (HRUS) became available. HRUS is non-invasive, painless, biologically safe, rapid to perform, and considerably less expensive then CT and MRI. This imaging technique is now being performed by rheumatologists, particularly in Europe, as part of the standard clinical assessment of patients. The application of HRUS to the early diagnosis and evaluation of treatment response heralds an era where rheumatologists will be able to better target and manage various rheumatologic conditions, in particular inflammatory arthritis.

\section{EFFUSION AND SYNOVITIS}

US allows visualization of inflamed sinovial tissue as a hypoechoic structure while effusion as an anechoic structure (Figure 1). Many studies have highlighted the ability of US in detecting early sinovial disease in both large and small joints and its superiority over clinic examination ${ }^{(2-4)}$. There have been several studies validating US against arthroscopy, MRI and scintigraphy. Backhaus et al. ${ }^{(4)}$ found more synovitis in the joints of the hand and wrist with US when compared to radiography and clinical examination and it was comparable with MRI. Brown et al. ${ }^{(5)}$ showed the relevance of US in the detection of sub-clinical synovitis in their study of patients with RA, who were in clinical remission as defined by the ACR criteria ${ }^{(6)}$. Almost half of the patients had US features of sub-clinical synovits in joints not thought to have any clinical synovitis. In a recent study of 80 patients with oligoarthritis ${ }^{(7)}$, two third of the patients had sub-clinical synovitis detected on US and one third could be reclassified as having polyarticular disease. Among those who were rheumatoid factor positive at baseline, $83 \%$ had evidence of sub-clinical sy-

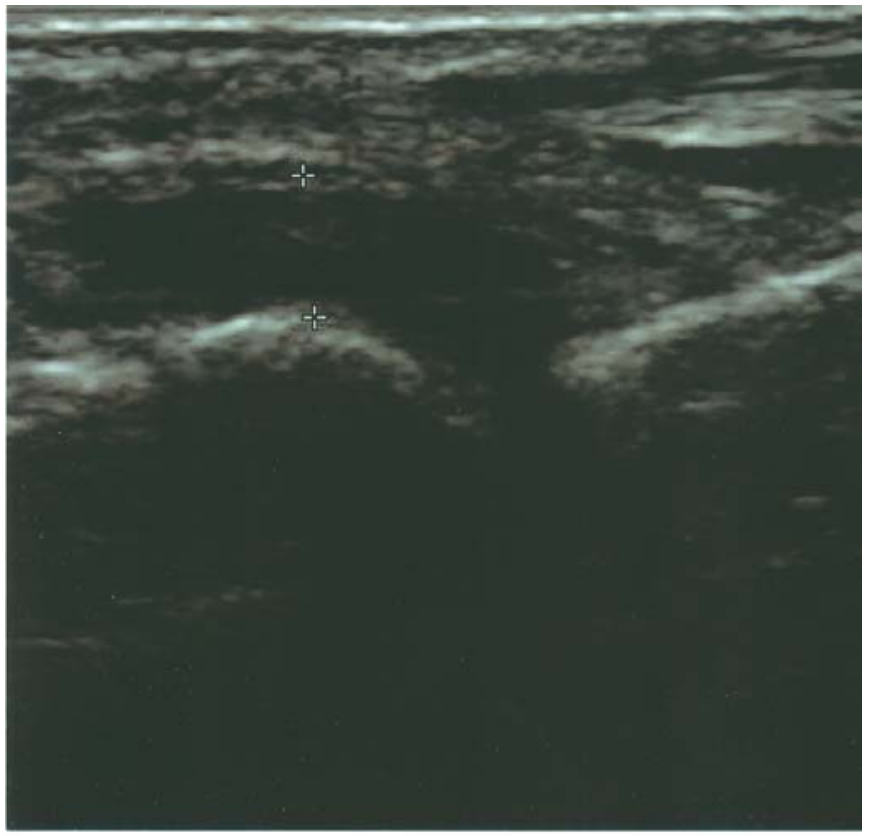

Figure 1 - Synovitis and effusion (in between the + signs) seen in the left third metacarpophalangeal joint of a patient with rheumatoid arthritis.

\footnotetext{
* Academic Department of Musculoskeletal Medicine, First Floor, Old Nurse's Home, The General Infirmary at Leeds, Great George Street, Leeds, LS1 3EX. United Kingdom.

1. Research Fellow in Rheumatology.

2. Maitre de Conference Universitaire, Praticien hospitalier in Rheumatology.

3. Research Fellow in Rheumatology.

4. Senior Lecturer in Rheumatology.

5. ARC Professor of Rheumatology.
}

Correspondence to: Prof. Paul Emery, MD FRCP, ARC Professor of Rheumatology, Academic Department of Musculoskeletal Medicine, First Floor, Old Nurse's Home, The General Infirmary at Leeds, Great George Street, Leeds, LS1 3EX. United Kingdom. Tel: +44(0)113 392 5068, Fax: +44(0)113 392 2896, e-mail: p.emery@leeds.ac.uk. 
novitis on US imaging. Of note, only $9 \%$ patients fulfilled the ACR criteria for RA at baseline but, the addiction of US findings (synovitis and erosions) increased this percentage to $50 \%$. This finding demonstrates a potential roe for US in assisting diagnosis of early RA and highlights an advantage over MRI (i.e., an ability to scan several joints at one time point). Clinical features of joint inflammation may not be present during this early stage as a result of subtleness af inflammation ${ }^{(8)}$ or a marked response to non-steroidal anti-inflammatory drugs (NSAIDs). In such situations, HRUS helps in identifying subclinical synovitis and allows reclassification of clinical oligoarthritis into polyarthritis ${ }^{(7)}$.

\section{BONY EROSION}

Furthermore, HRUS may detect bony erosions in affected joints when conventional radiography remains normal ${ }^{(9)}$. Erosion is defined as a cortical "break" or defect with an irregular floor seen in longitudinal and transverse planes (Figure 2). Although MRI is as good as HRUS, if not better, in detecting synovitis and bony erosions ${ }^{(10)}$, HRUS is cheaper and easily accessible in outpatient setting. The use of HRUS at early stage in identifying the presence of sub-clinical bony damages provides strong basis for early initiation of DMARD therapy. A study by Wakefield et al. ${ }^{(9)}$ found that US was a reproducible technique and detected 3.5 times as many erosions as radiography; this difference was even grater with early disease. The superiority of US over

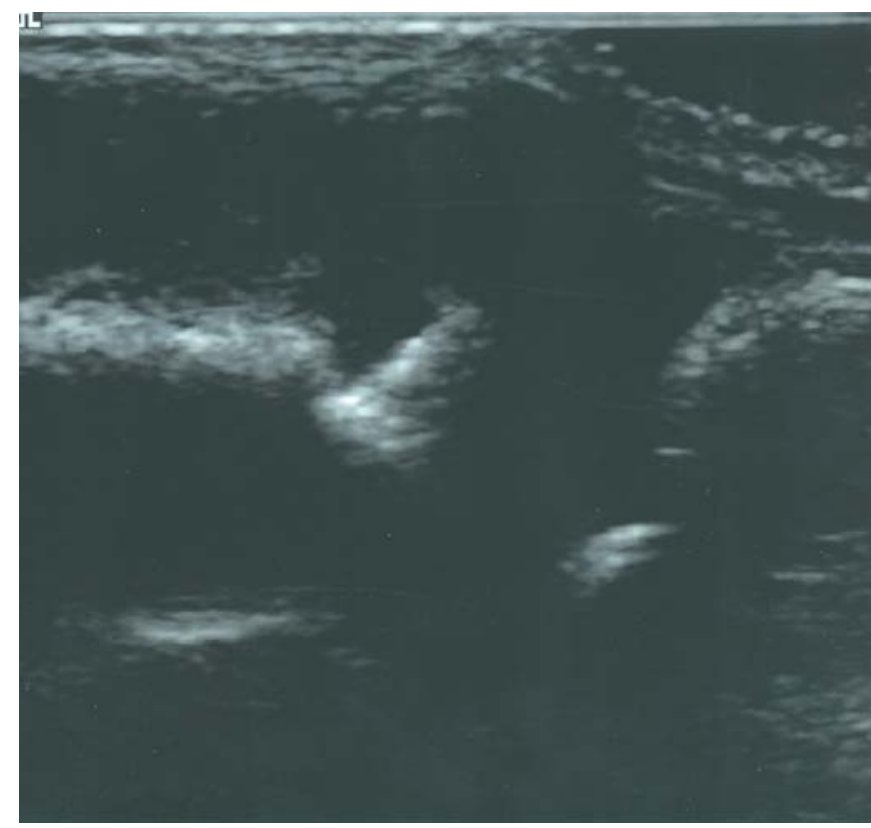

Figure 2 - An erosion seen on the dorsal aspect of the left third metacarpophalangeal joint of the same patient as in figure 1. conventional radiography (CR) is explained by the multiplanar capability of US and the fact that US can detect smaller erosions. MRI was also used to assess the radial aspect of the 2 nd MCP heads in 25 patients with early disease. All 10 MRI erosions corresponded exactly with US erosions. It is of interest to note that US detected 3 additional erosions. These can be explained by the superior spatial resolutions of US compared to MRI. A more recent study by Alarcon et al. ${ }^{(11)}$ confirmed other diagnosis findings.

Reports on the value of HRUS in osteoarthritis suggest that may aid in diagnosis and assessment of severity of the disease. It allows assessment of joint space narrowing, osteophytes, Baker's cyst formation and its complication, and hyaline cartilage thickness of the trochlear groove (since the other knee articular surface are not directly accessible to the probe). High prevalence of synovitis in the symptomatic osteoarthritis knees confirmed previous clinical findings ${ }^{(12)}$. Use of US in other rheumatologic conditions is also developing. Its ability in assessing the skin thickness ${ }^{(13-15)}$ and vascularity changes ${ }^{(16)}$ in systemic sclerosis had been reported. There has also been suggestion of its use in the management of myosistis ${ }^{(17)}$.

HRUS does not involve ionizing radiation and is safe to be repeated as often as necessary on a number of different joints making it ideal for patient follow-up. HRUS also allows clinicians to distinguish inflammatory and non-inflammatory diseases with more confidence, predict which patients have a poorer prognosis and require more aggressive early therapy and develop a more effective and appropriate treatment plan for the patients. A study by Karim et al. demonstrated $50 \%$ of clinical decisions are changed with the addition of the information from HRUS among those who were referred for HRUS examination ${ }^{(18)}$. In our unit, HRUS has been offered to rheumatology patients since 1997. Approximately 2000 patients a year have been benefited from it. Patients were seen by rheumatologists and had HRUS scanning of the joints done at the same clinic visit, if indicated. This not only provides a higher quality of care to patients with rheumatologic conditions, it also reduces the number of hospital visits for patients.

\section{POWER DOPPLER SONOGRAPHY}

Power Doppler Sonography (PDS) is playing an increasing role in the assessment of disease activity of inflammatory arthritis. Because PDS provides higher sensitivity to lowvolume, low velocity blood flow at microvascular level, it is particularly useful for detecting changes of blood volume in sinovial issue and enthesitis, reflecting the degree of inflammation (Figure 3) and thus allowing the evaluation 
of the response to therapy. In addition, PDS signal is independent of the transducer angle and thus does not have the problem of aliasing, an artifact as a result of inadequate signal sampling, and also much reduced background noi$\mathrm{se}^{(19)}$. PDS also improved of vessel characteristics that are not well visualized with colour-flow Doppler imaging. With the ability to identify low-velocity blood flow, PDS increases the specificity of HRUS in differentiating sinovial hypertrophy form fibrobtic sinovial tissues, blood clots, and complex effusion. The sensitivity of PDS can be further enhanced with the use of intravenous micro-bubble echo contrast agents ${ }^{(20)}$. Validation of PDS against histopathology ${ }^{(21,22)}$ and MRI ${ }^{(23)}$ had been published and it correlates well with the degree of the synovitis. Use of PDS in monitoring disease activity ${ }^{(24,25)}$ and treatment response ${ }^{(26-28)}$ in rheumatoid arthritis has also been reported. The value of PDS has also been assessed in enthesitis ${ }^{(29)}$, spondyloarthorthopathy ${ }^{(30)}$, myositis ${ }^{(31)}$.

\section{US-GUIDED PROCEDURES}

The use of US-guided procedures during daily clinical practice is also of relevance to rheumatologists. US can visualize deep joints that are not accessible to clinical examination, and help in establishing the diagnosis of effusion. Moreover HRUS offers the opportunity for aspiration and biopsies in the same setting especially when sepsis in suspected. US can be useful for diagnostic and therapeutic

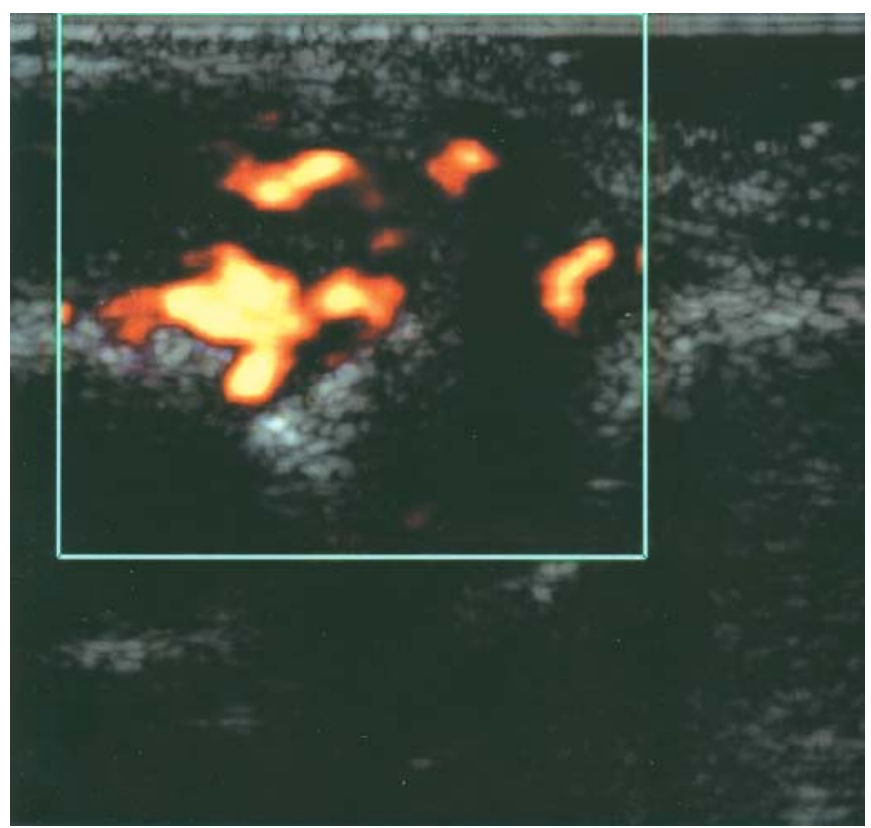

Figure 3 - Power Doppler signal seen in the synovitis and within the erosion of the left third metacarpophalangeal joint of the same patient as in figure 1. procedures. Steroid injection influences the efficacy ${ }^{(32,33)}$. Without imaging-guidance, the placement of needle was correct in only $50 \%$ of the time ${ }^{(32)}$. It has been used to direct biopsy needles in erosions and enthesial sites. In addition to the imaging guidance provided, the portability of the machine and lack of radiation allow more flexibility in aspiration, injection or biopsy.

It is particularly important for young rheumatologists to have a good understanding of functional limb anatomy in order to be able to manage regional pain syndromes efficiently and be experts in soft tissue rheumatology. The introduction of HRUS in academic rheumatology enhances the teaching of functional anatomy to rheumatology trainees. Dynamic HRUS provides detailed real-time sequential knowledge of the live functional anatomy that cannot easily be obtained otherwise. Trainees can observe the movement of muscles and tendons in relation to each other during the movement of interest. Many world-renown rheumatologic training canters have included HRUS as part of the core curriculum of training for young rheumatologists. In fact, some even consider it a requirement for rheumatologists ${ }^{(34)}$ (since it may be regarded) as an extension of physical examination.

In order to use HRUS in daily practice of rheumatology, its limitations must be well understood. The interactive and dynamic process of HRUS imaging means that such procedures are observer-dependent. This emphasizes the need for ultrasonographers to have adequate training at established rheumatology centers before service is provided. The characteristic of US also means that is impossible to visualize structures behind or within bones. Some structures, such as sacroiliac joints and hips, cannot be assessed adequately with the available transducers. The presence of artifacts, such as aniosotropy, must not be overlooked and at time may assist in identification of various structures, such as tendons or ligaments.

Worldwide, the use of HRUS in assisting the management of rheumatologic conditions, especially inflammatory arthritis, is growing rapidly. The availability of new, efficacious, expensive biologic therapies for inflammatory arthritis means the accurate diagnosis and monitoring of these patients has become even more important, particularly if there is a potential for stopping or reducing the use of these therapies among patients who are in remission. It is possible that HRUS in rheumatology may achieve a status similar to echocardiography in cardiology in future. With the advances in the technologies, the growth of HRUS in rheumatology must not be overlooked, especially when improved patient care and better disease outcome are the goals for all rheumatologists. 


\section{REFERENCES}

1. McDonald DG, Leopold GR. Ultrasound B-scanning differentiation of Baker's cyst and thrombophlebitis. Br J Radiol 1972; 45(538):729-32.

2. Koski JM. Ultrasonographic evidence of hip synovitis in patients with rheumatoid arthritis. Scand J Rheumatol 1989;18(3):127-31.

3. Conaghan, Wakefield R, O'Connor P, Gibbon W, Emery P. The metacarpophalangeal joints in early rheumatoid arthritis: a comparison of clinical, radiographic, MRI and ultrasonographic findings, Ann Rheum Dis 1999;58(Suppl).

4. Backhaus M, Kamradt T, Sandrock D, et al. Arthritis of the finger joints- a comprhensive approach comparing conventional radiography, scintigraphy, ultrasound and contrast-enhnaced magnetic resonance imageing. Arthritis Rheum 1999;42:1232-45.

5. Brown AK, Quinn MA, Karim Z, et al. Neither the ACR remission criteria nor the disease activity score accurately define true remission in rheumatoid arthritis. Arthritis Rheum 2002;46 Suppl 9:243.

6. Pinals RS, Mais AT, Larsen RA. Preliminary criteria for clinical remission in rheumatoid arthritis. Arthritis Rheum 1981;24(10): 1308-15.

7. Wakefield RJ, Green MJ, Helena MO, et al. Should oligoarthritis be reclassified? - Ultrassound reveals high prevalence sub-clinical disease. Ann Rheum Dis 2003; (in press).

8. Wakefield RJ, Green M, Gibbon WW, et al. High-resolution ultrasound defined sub-clinical synovitis - predictor of outcome in early oligo arthritis? Arthritis Rheum 1998;41 Suppl 9:246.

9. Wakefield RJ, Gibbon WW, Conaghan PG, et al. The value of sonography in the detection of bone erosions in patients with rrheumatoid arthritis - a comparison with conventional radiography. Arthritis Rheum 2000;43:2762-70.

10. McGonagle D, Conaghan PG, O'Connor P, et al. The relationship between synovitis and bone changes in early untreated rheumatoid arthritis: a controlled magnetic resonance imaging study. Arthritis Rheum 1999;42(8):1706-11.

11. Alarcon GS, Lopez-Ben R, Moreland LW. High-resolution ultrasound for the study of target joints in rheumatoid arthritis. Arthritis Rheum 2002;46(7):1969-70; author reply 1970-1.

12. Hukisson EC, Dieppe PA, Tucker AK, Cannel LB. Another look at osteoarthritis. Ann Rheum Dis 1979;38(5):423-8.

13. Cosnes A, Anglade MC, Revuz J, Radier C. Thieteen-megahertz ultrasound probe: its role in diagnosing localized scleroderma. Br J Dermatol 2003;148(4):724-9.

14. Hesselstrand R, Westergreen-Thorsson G, Scheja A, Wildt M, Akesson A. The association between changes in skin echogenicity and the fibroblast production of biglycan and versican in systemic sclerosis. Clin Exp Rheumatol 2002;20(3)301-8.

15. Scheja A, Akesson A. Comparisson of high frequency $(20 \mathrm{MHz})$ ultrasound and palpation for the assessment of skin involvement in systemic sclerosis (scleroderma). Clin Exp Rheumatol 1997; 15(3):283-8.

16. Keberle M, Tony HP, Jahns R, Hau M, Haerten R, Jenett M. Assessment of microvascular changes in Raynaud's phenomenon and connective tissue disease using color Doppler ultrasound. Rheumatology (Oxford) 2000;39(11):1206-13.

17. Fleckenstein JL, Reimers CD. Inflammatory myopathies: radiologic evaluation. Radiol Clin North Am 1996;34(2):427-38, XII.
18. Karim Z, Wakefield RJ, Conaghan PG, et al. The impact of ultrasonography on diagnosis and management of patients with musculoskeletal conditions. Arthritis Rheum 2001;44(12):2932-3.

19. Rubin JM, Bude RO, Carson PL, Bree RL, Adler RS. Power Doppler US: a potentially useful alternative to mean frequencybased color Dopler US. Radiology 1994;190(3):853-6.

20. Blomley MJ, Cooke JC, Unger EC, Monaghan MJ, Cosgrove DO. Microbubble contrast agents: a nem era in ultrasound. BMJ 2001; 322(7296):1222-5

21. Schmidt WA, Volker L, Zacher J, Schlafke M, Ruhnke M, Gromnica-ihle E. Colour Doppler ultrasonography to detect pannus in kenee joint synovitis. Clin Exp Rheumatol 2000;18(4):439-44.

22. Walther M, Harns H, Krenn V, Radke S, Faehndrich TP, Gohlke F. Correlation of power Doppler sonography with vascularity of the sinovial tissue of the knee joint in patients with osteoarthritis and rheumatoid arthritis. Arthritis Rheum 2001;44(2):331-8.

23. Szkudlarek M, Court-payen M, Strandberg C, Klarlund M, Klausen T, Ostergaard M. Power Doppler ultrasonography for assessment of synovitis in the metacarpophalangeal joints of patients with rheumatoid arthritis: a comparison with dynamic magnetic resonance imaging. Arthritis Rheum 2001;44(9):2018-23.

24. Qvistgaard E, Rogind H, Torp-pedersen S, Terslev L, DanneskioldSamsoe B, Bliddal H. Quantitative ultrasonography in rheumatoid arthritis: evaluation of inflammation by Doppler technique. Ann Rheum Dis 2001;60(7):690-3.

25. Carotti M, Slaffi F, Manganelli P, Salera D, Simonetti B, Grassi W. Power Doppler sonography in the assessment of synovial tissue of the knee joint in rheumatoid arthritis: a preliminary experience. Ann Rheum Dis 2002;61(10):877-82.

26. Hau M, Kneitz C, Tony HP, Keberle M, Jahns R, Jenett M. High resolution ultrasound detects a decrease in pannus vascularisation of small finger joints in patients with rheumatoid arthritis receiving treatment with soluble tumour necrosis factor alpha receptor (etanercept). Ann Rheum Dis 2002;61(1):55-8.

27. Newman JS, Laing TJ, McCarthy CJ, Adler RS. Power Doppler sonography of synovitis: assessment of therapeutic responsepreliminary observations. Radiology 1996;198(2):582-4.

28. Stone M, Bergin D, Whelan B, Maher M, Murray J, McCarthy C. Power Doppler ultrasound assessment of rheumatoid hand synovitis. J Rheumatol 2001;28(9):1979-82.

29. D'Agostino MA, Said Nahal R, Hacquard-Bouder C, Brasseur JL, Dougados M, Breban M. Assessment of peripheral enthesitis in the spondylarthropathies by ultrassonography combined with power Doppler: a cross-sectional study. Arthritis Rheum 2003;48(2):523-33.

30. D'Agostino MA, Breban M, Said-Nahal R, Dougados M. Refractory inflammatory heel pain in spondylarthropathy: a significant response to infliximab documented by ultrasound. Arthritis Rheum 2002;46(3):840-1, author reply 841-3.

31. Meng C, Adler R, Pterson M, Kagen L. Combined use of power Doppler and gray-scale sonography: a new technique for the assessment of inflammatory myopaathy. J Rheumatol 2001;28(6): 1271-82

32. Jones A, Regan M, Ledingham J, Pattrick M, Manhira A, Doherty $M$. Importance of placement of intra-articular steroid injections. Bmj 1993;307(6915):1329-30.

33. Eustace JA, Brophy DP, Gibney RP, Bresnihan B, FitzGerald O. Comparison of the accuracy of steroid placement with clinical outcome in patients with symptoms. Ann Rheum Dis 1997;56(1):59-63.

34. Canoso JJ. Ultrasound imaging-a requirement for rheumatologists. J Rheumatol 2002;29(4):862-3. 